\title{
Science and Technology Backyard improves farmers' productivity
}

\author{
Jianchang Yang \\ College of Agriculture, Yangzhou University, Yangzhou 225009, China
}

Received October 6, 2016; accepted October 11,2016; published online October 31, 2016

Citation: Yang, J. (2016). Science and Technology Backyard improves farmers' productivity. Sci China Life Sci 59, 1348-1349. doi: 10.1007/s11427-016-0301-x

Science and technology $(\mathrm{S} \& \mathrm{~T})$ are the first productivity. However, S\&T must be mastered by users and then can become the practical productivity. Annually there are about 25,000 registered S\&T achievements in China, but the transformation efficiency from these achievements into practical productivity is less than $50 \%$ (Zhang and Guo, 2010). In the rural areas of China, the transformation efficiency from agricultural S\&T achievements into farmers' productivity is lower, due to the small size of farms, lack of knowledge, information and resources and other factors. Statistics show that there are 6,000-7,000 agricultural S\&T achievements available annually in China, but the transformation efficiency is only $30 \%-40 \%$, far below the level of $70 \%-90 \%$ in developed countries (Zhai, 2015). Chinese agricultural scientists have developed many new technologies for high yield and high efficiency crop management and obtained high yield in their test fields. However, the yield in farmers' fields is only about $60 \%$ of that harvested in the test fields, with large yield gaps (Chen et al., 2014). The fact that the agricultural S\&T achievements made by scientists can not be used by farmers not only causes a huge waste of investment in scientific research, but also hinders the improvement in farmers' productivity and living standards. How to transform S\&T into farmers' productivity and income is an urgent problem to be solved in developing countries, including China.

To solve this problem, Professor Fusuo Zhang and his research team in China Agricultural University established the first Science and Technology Backyard (STB) in Quzhou

*Corresponding author (email: jcyang@yzu.edu.cn)
County, Hebei Province, China in 2009. Taking the STB as a platform, they developed crop management technologies suitable for local conditions and imparted the new technologies of high yield and high efficiency crop management to the local farmers, and thereby transformed S\&T into farmers' productivity and income. It is reported that after the establishment of the STB, the adoption rate of high yield and high efficiency crop management technology in Quzhou increased from $17.9 \%$ in 2009 to $53.5 \%$ in 2014 ; and the average yield increased from $62.8 \%$ of the attainable level in 2009 to $79.6 \%$ in 2014 countywide; and the farmers' income increased by $79 \%$ during the five years from 2009 to 2014 (Zhang et al., 2016). So far, 81 STBs have been established in 21 provinces of China, and all tremendously increased crop yields and farmers' income.

Why can the STB improve farmers' productivity and income? Its functions and roles need to be further recognized. Three points, however, merit attention. Firstly, STB plays a role in linking scientists and small farmers. Usually, scientists' research is disconnected from farmers' application, and the technology developed by scientists is difficult to be used by farmers. The STB provides a platform at which scientists can communicate with farmers face to face, develop high yield and high efficiency crop management together with farmers, and directly impart their technology to farmers, and accordingly, increase farmers' knowledge. Secondly, STB plays a role in integrating resources from various departments. The transformation of S\&T into farmers' productivity needs the participation of various departments, such as local governments, enterprises and agro-extension 
services. The STB builds a platform for various departments to be integrated and to form a cohesive force, which can accelerate the transformation of S\&T into farmer's productivity. Thirdly, STB plays a role in cultivating high-level talents. Graduates in China's agricultural universities have solid theoretical knowledge. However, they have less practical training and weaker professional skills. One of the important functions for STB is cultivating graduates. On the one hand, graduates through participating in STB can reinforce their practical foundation, improve their professional skills and get overall development; on the other hand, graduates via STB can contribute their knowledge and ability to the improvement in farmers' productivity and living standards.

The establishment of STB in rural areas provides an effective way to improve farmers' productivity and income not only in China, but also in other developing countries in the world. However, the present number of STBs is too limited to meet the needs of more than 800 million farmers in China. It needs the concerted efforts of governments, enterprises and scientific research organizations to explore together to further develop STB and to play its full functions and roles.

Compliance and ethics The author(s) declare that they have no conflict of interest.

Chen, X., Cui, Z., Fan, M., Vitousek, P., Zhao, M., Ma, W., Wang, Z., Zhang, W., Yan, X., Yang, J., Deng, X., Gao, Q., Zhang, Q., Guo, S., Ren, J., Li, S., Ye, Y., Wang, Z., Huang, J., Tang, Q., Sun, Y., Peng, X., Zhang, J., He, M., Zhu, Y., Xue, J., Wang, G., Wu, L., An, N., Wu, L., Ma, L., Zhang, W., and Zhang, F. (2014). Producing more grain with lower environmental costs. Nature 514, 486-489.

Zhai, J.L. (2015). Characteristics, problems and countermeasures of agricultural scientific and technical achievements transformation in China. Bull Chin Acad Sci 30, 378-385.

Zhang, J.F., and Guo, R. (2010). The current analysis and policy recommendations for the transformation of scientific and technological achievements. Chin Soft Sci S2, 137-141, 165.

Zhang, W., Cao, G., Li, X., Zhang, H., Wang, C., Liu, Q., Chen, X., Cui, Z., Shen, J., Jiang, R., Mi, G., Miao, Y., Zhang, F., and Dou, Z. (2016). Closing yield gaps in China by empowering smallholder farmers. Nature $537,671-674$.

Open Access This article is distributed under the terms of the Creative Commons Attribution License which permits any use, distribution, and reproduction in any medium, provided the original author(s) and source are credited. 